\section{Rudeness and respect in medicine}

\author{
John Launer
}

The idea of holding a randomised clinical trial of rudeness is highly original, but a well-designed one was conducted recently in Israel and has been widely reported. ${ }^{1}$ Twenty-four neonatal intensive care teams participated in a training simulation exercise, centred on a preterm infant with necrotising enterocolitis who was deteriorating. Participants were told that a foreign expert on teamwork would observe them working together. Teams were then randomly assigned to two groups. One group first listened to a recorded message from the expert, who made rude comments about the quality of medicine in Israel. Once the simulation began, the expert made further disparaging remarks, saying that some staff he had observed in Israel "wouldn't last a week" in his department, and he hoped he would not get sick while in Israel. A control group heard a different, neutral message from the same expert before the simulation, and he made no rude or disparaging comments later.

Three independent judges, blinded to which message the teams had heard, observed videotapes of the simulation sessions afterwards and assessed team performance, information-sharing, and help-seeking. The results showed that members of the teams that were exposed to rudeness scored significantly lower on diagnostic and procedural performance. The authors of the study pointed out how rudeness may have an adverse effect on cognitive performance, leading to impaired diagnostic thinking and dexterity, as well as reducing the collaboration needed for good care. They wrote: "rude behaviours regularly experienced by medical practitioners", although seemingly benign, can result in "potentially devastating outcomes" for patients. They called for policy makers to consider the role played by the verbal aggression to which medical professionals are routinely exposed.

While an intervention trial of rudeness like this may be unusual, there have been many qualitative studies of negative behaviour in health service settings and they show similar results. Doctors who have experienced bullying are more likely to report having made serious medical

Correspondence to Dr John Launer, Faculty Development, Health Education England, Stewart House, 32 Russell Square, London WC1B 5DN, UK; john.launer@nwl.hee.nhs.uk

\section{THREAT TO SAFETY}

mistakes in the previous month. ${ }^{2}$ Medical students who were bullied during their training are more likely to mistreat patients in their turn. ${ }^{3}$ Negative behaviour arises not only because of individuals who are deviant or under exceptional stress. More commonly, it happens when whole groups, teams or institutions develop a negative culture and climate. ${ }^{4}$ It arises in organisations where bad behaviour is tolerated by managers, or modelled by them, and is then allowed to become the norm.

The problem may extend more widely than single organisations. A working group on professionalism from Harvard Medical School has suggested that disrespect is pervasive in health care and constitutes a widespread threat to the safety and wellbeing of patients and health care workers. ${ }^{5} 6$ They argue that disrespectful treatment is "so common and so intimately woven into the health care environment and everyday work that they are accepted as normal and often are not recognised as disrespect." As examples, they cite long work hours, high workloads, physical hazards, and psychological intimidation that affect doctors, nurses and all health professionals. Taken together, these increase the likelihood that staff will make errors that harm patients or themselves, and diminish meaning or satisfaction in their daily work. As far as patients are concerned, disrespect manifests itself as "being made to wait for appointments, receiving patronising and dismissive answers to questions, not being given full and honest disclosure when things go wrong, and not receiving the information they need to make informed decisions." The authors propose that a culture of respect is a precondition for the changes needed to make health care safe.

Almost everybody who has addressed the subject advises that any remedy for disrespect must be systemic, and involve wholehearted engagement by senior leadership. The Harvard working group make comparisons with so-called "highreliability organisations" like those in the aviation and nuclear power industries, where everyone understands that small failures can lead to catastrophic outcomes. Such organisations all emphasize the relational aspects of culture. These include person-centredness, support for co-workers, friendliness, openness in personal relations, creativity, trust and resilience. The task of changing the culture of medicine in this direction, the Harvard team argues, must start with medical school deans and hospital chief executives. As well as setting out clear codes of conduct and policies, leaders need to engage frontline workers by ensuring safe, simple and productive reporting systems, together with prompt, predictable and appropriate responses. The authors emphasise the urgency of this task, concluding: "The time has come for health care organisations to do something about this invidious problem and cultivate a climate of respect." There are probably few medical school deans and hospital chief executives who would disagree with this in principle, and few frontline workers would do so either.

At the same time, from several years' experience of carrying out team facilitation in health care organisations, I would say that there are two further perspectives that need to be considered when addressing rudeness and disrespect. One perspective is that of ethics and the other is political. From the point of view of ethics, each one of us is capable of rudeness, or at least of being thoughtless and causing offence to colleagues or patients unintentionally. It requires moral courage to acknowledge when this happens, and to be willing to apologise and change one's speech and actions accordingly. Without being explicit about this or invoking ideas of virtue, ${ }^{7} 8$ institutional attempts to contain negative behaviour may decline into bureaucracy and rhetoric only.

Looking from the perspective of politics, health services do not exist within a bubble. They are influenced by norms in the society around them. When a government in any part of the world operates through confrontation and aggressive talk, it becomes proportionately more difficult for organisations to foster respect, or for individual health workers to express their capacity for kindness. Tackling rudeness and disrespect properly may require contrition both on a personal level, and at a political one.

Twitter Follow John Launer at @JohnLauner

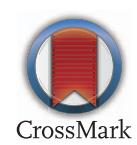

To cite Launer J. Postgrad Med J 2016;92:307-308.

Postgrad Med J 2016;92:307-308.

doi:10.1136/postgradmedj-2016-134127 


\section{On reflection}

\section{REFERENCES}

1 Riskin A, Erez A, Foulk TA, et al. The impact of rudeness on medical team performance: a randomized trial. Pediatrics 2015;136:487-95.

2 Paice $E$, Smith D. Bullying of trainee doctors is a patient safety issue. Clin Teacher 2009;6:13-7.

3 Moscarello R, Margaittai KJ, Rossi M. Differences in abuse reported by female and male Canadian medical students. Can Med Assoc J 1994;150: 357-63.
4 Illing JC, Carter M, Thompson NJ, et al. Evidence synthesis on the occurrence, causes, consequences, prevention and management of bullying and harassing behaviours to inform decision making in the NHS. Durham: Durham University, 2012. http://www.netscc. ac.uk/hsdr/files/project/SDO_FR_10-1012-01_V06.pdf (accessed 26 Mar 2016)

5 Leape LL, Shore MF, Dienstag JL, et al. A culture of respect, part 1: the nature and causes of disrespectful behaviour by physicians. Acad Med 2012;87:845-42.
6 Leape LL, Shore MF, Dienstag JL, et al. A culture of respect, part 2: creating a culture of respect. Acad Med 2012;87:853-58.

7 Girod J, Beckman AW. Just allocation and team loyalty: a new virtue ethic for emergency medicine. J Med Ethics 2005;31:567-70.

8 Larkin GL, Iserson K, Kassutto Z, et al. Virtue in emergency medicine Acad Emerg Med 2009;16: $51-5$. 